\section{Major Disaster Medical Response - What Goes Wrong and What We Can Do About It \\ William Lokey}

U.S. Federal Emergency Management Agency (FEMA), Washington, DC, USA

Disasters happen - they are a fact of life. Communities and organizations have a responsibility to be prepared for disaster, especially when it comes to medical care for disaster victims. But, what should we be doing to prepare?

There are many things we could do in the way of training and planning. But if we look at case studies and disaster research from historic point of view, and at the recent disasters in the United States, we can see patterns of problems in major disaster medical responses that seem to occur over and over again. Drawing from the lessons learned from these events, we are able to get guidance as to what are the most effective and efficient strategies for disaster preparedness and response.

This presentation will highlight lessons learned from the past and present ideas and concepts to improve major disaster medical planning and response in the future. It will cover what disaster research has shown to be common human and organizational behaviors and dynamics in disasters, and will offer suggestions for improving community disaster response systems and medical response to major disasters.

Keywords: community; disasters; lessons; patterns; planning; preparedness; responses; training
Anti-Personnel Landmines - The Explosive Mixture of Medicine and Politics

Dr. Ronald Stewart 